\title{
Building a Robot Course
}

Jonathan Hoe ${ }^{1}$

${ }^{1}$ Affiliation not available

May 3, 2021

\begin{abstract}
This course will allow students to integrate STEM concepts and critical thinking into engineering design, circuit building and programming to build an eco-friendly robot with a public service purpose.
\end{abstract}

\section{Building a Robot}

\section{Suggested Time: 120 minutes}

\section{Overview}

Students will apply their STEM knowledge to build a real robot.

\section{Define: What is Robotics?}

Students will collaborate in groups to research and derive their own definition of what is a robot, what are the various types of robots (both fiction and real life), how robots can help in our daily life through an inquiry based learning approach and present to the class. They will learn and be guided by Teachers to explore how Science, Technology, Engineering, Arts, Math could be applied to the design, development and application of robots.

\section{Vocabulary}

- Arduino

- Raspberry Pi

\section{Objectives}

- Students will acquire basic electrical engineering, mechanical engineering and programming skills. 
- Students will gain $21^{\text {st }}$ century key skills such as problem solving, creativity, analytical thinking, collaboration, communication, ethics when they design and make their robots.

- Students will think about the real-world beneficial and practical applications of robotics.

\section{Science Topics covered}

\section{Forces and Interactions}

- Forces and Motion

- Types of Interactions

- Definitions of Energy

- Defining and Delimiting Engineering Problems

- Optimizing the Design Solution

\section{Energy}

- Definitions of Energy

- Conservation of Energy and Energy Transfer

- Relationship Between Energy and Forces

\section{Science and Engineering Practices:}

- Planning and Carrying Out Investigations

- Analyzing and Interpreting Data

- Using Mathematics and Computational Thinking

- Constructing Explanations and Designing Solutions

- Science Models, Mechanisms, and Theories Explain Natural Phenomena

\section{Human Sustainability:}

- Natural Resources

- Human Impacts on Earth Systems

- Developing Possible Solutions

\section{Cross-Cutting Concepts:}

- Influence of Science, Engineering, and Technology on Society and the Natural World

- Science Is a Human Endeavor

- Science Addresses Questions About the Natural and Material World

- Energy and Matter

\section{Science Standards}

- Inquiry, Reflection, and Social Implications

\section{Technology Standards}

- Creativity and Innovation

- Research and Information Literacy

- Critical Thinking, Problem Solving, and Decision Making

- Digital Citizenship 


\section{Required Project Materials}

- Arduino and Raspberry Pi supplies, depending on the projects chosen

\section{Required Resources}

- Arduino: https://www.arduino.cc

- Raspberry Pi: https://www.raspberrypi.org

\section{Pre Lesson Homework}

- Teachers to ask students to brainstorm on the ethical use of robots and how can the public /society at large benefit from a robot and guide the class toward building a feasible prototype.

\section{Lesson 1: Idea Generation}

\section{Part 1: Engineering Design Process: Define, Identify, Brainstorm, Select, Prototype (60 mins)}

1. Students to list down the pros and cons of the various robots used by the different industries. Why do we need robots? Does the benefits outweigh the risks? What are their limitations or challenges and any ethical or privacy concerns?

2. Teachers to guide the students on the robot concepts with a public-service objective. With the students basic knowledge in circuit work, and programming, are the robot models workable? Teachers to work with students to build on some prototype models in which they envisioned to build. It is ok for them to fail and rebuild.

3. Teachers to get students to think and compile a list of materials needed for the project. Recommended recyclables from home. Teachers to conclude on the feasible materials for students to bring to create their robots.

4. Students to collaborate in groups and come up with a design draft for the project. Every group to have a distinct robot.

\section{Lessons 2: Idea Building}

\section{Part 2: Engineering Design Process: Test, Iterate, and Communi- cate $(60$ mins $)$}

1. Teachers to review and discuss the groups' designs and trigger their inquisitive minds by asking open ended questions on the limitations and explore endless possibilities. Teachers to get groups to do a cross review on each other groups' designs so students can explore other possibilities and make adjustments.

2. Students will then construct their robots.

3. Teachers to give ample time for construction, testing, revisions and improvement suggestions for their robots.

4. Students to showcase their robots demonstration in a school exhibition and allow them to bring back to discuss and show their parents for a review. 